\title{
Role of saccadic analysis in the diagnosis of multiple sclerosis in the era of magnetic resonance imaging
}

\author{
G TEDESCHI, S AllocCA, A Di Costanzo, A DiAno,* V BonAvita \\ From the Institute of Neurological Sciences, First School of Medicine, and Institute of Radiology, ${ }^{*}$ Second \\ School of Medicine, University of Naples, Naples, Italy
}

SUMMARY Magnetic resonance imaging (MRI) has recently been recognised as the most sensitive method with which to detect clinically silent lesions in patients affected by multiple sclerosis. Visually guided horizontal saccadic eye movements (SEM) were studied, together with MRI, in 57 multiple sclerosis patients. A very similar sensitivity was found for both MRI (78.2\%) and SEM analysis (76.3\%). Significant associations between peak saccadic velocity and brain stem signs and between saccadic latency and visual signs were observed.

Multiple sclerosis is diagnosed mainly on the clinical demonstration of central nervous system (CNS) white matter disease, with multiple lesions occurring at different times and at different anatomical sites. McAlpine' $\mathbf{s}^{1}$ classification for multiple sclerosis is still one of the most used, and it takes into account only clinical and historical findings.

Advances in laboratory procedures, however, have made available new tools with which to detect clinically unsuspected lesions. Some of these methods have reached such a wide acceptance that they have been included in the newer classification criteria for multiple sclerosis proposed by Poser $e t a l^{2}$ which give to paraclinical findings the same importance as clinico/ historical features in the diagnosis of multiple sclerosis.

The most common laboratory tests include cerebrospinal fluid examination, evoked potentials and computed tomographic scanning, and, more recently, magnetic resonance imaging (MRI). Computer analysis of saccadic eye movements (SEM) has also been used to detect clinically silent lesions in multiple sclerosis patients, ${ }^{3-7}$ since it offers the possibility of studying more than one neurophysiologic system and can give a quantitative estimation of CNS involvement. $^{8}$

Several parameters can be extracted from horizontal SEM: peak saccadic velocity (PSV) can be regarded as an indicator of the function of the paramedian

Address for reprint requests: Dr G Tedeschi, Institute of Neurological Sciences, First School of Medicine, University of Naples, Via Pansini 5, 80131 Naples, Italy.

Received 3 February 1989.

Accepted 28 March 1989 pontine reticular formation; saccade accuracy (SA) can be related to cerebellar function and saccadic latency (SL) can be referred to neural conduction times in the entire visual oculomotor pathways. ${ }^{8}$ Furthermore, interocular differences have proved to be an extremely sensitive indicator of conjugacy disorders owing to the involvement of the medial longitudinal fasciculus, so that bilateral monocular recordings ${ }^{9}$ can detect subclinical internuclear ophthalmoparesis (SINO). Recent studies ${ }^{10-14}$ have suggested that MRI is more sensitive than evoked potentials and cerebrospinal fluid examination for establishing the diagnosis of multiple sclerosis.

The present study aimed to assess if, with the availability of MRI, SEM analysis can still be regarded as a useful tool for the diagnosis of multiple sclerosis.

\section{Patients and methods}

Fifty seven patients were classified as having multiple sclerosis on the basis of McAlpine criteria.' Their general characteristics are summarized in table 1. MRI and SEM analysis were performed on the same day. Signs and symptoms were divided into brainstem (BS), sensory (S), visual (V), cerebellar (CBL) and pyramidal (P). Patients taking medications that could effect SEM (such as benzodiazepines, anticholinergic agents, baclofen) and patients with clinically evident deficits of SEM (ocular dysmetria and slow saccades) were not included in the study. SEM were generated by a personal computer and recorded by electro-oculography according to a method described by Griffiths et al. ${ }^{15}$ Simultaneous monocular and binocular recordings were obtained, the signal from the electrodes was amplified by a differential DC amplifier and low pass filtered $(50 \mathrm{~Hz},-3 \mathrm{~dB})$ before being digitised to 8-bit resolution at a sampling rate of $250 \mathrm{~Hz}$ and stored in the computer. Saccade sequences lasted 2 
Table 1 General characteristics of patients

\begin{tabular}{|c|c|c|c|}
\hline $\begin{array}{l}\text { Clinical } \\
\text { category }\end{array}$ & $\begin{array}{l}\text { No of } \\
\text { patients }\end{array}$ & $\begin{array}{l}\text { Age (yrs) mean, } \\
S D \text { (range) }\end{array}$ & $\begin{array}{l}\text { Disease } \\
\text { duration (yrs) } \\
\text { mean, SD (range) }\end{array}$ \\
\hline Definite & 32 & $\begin{array}{l}34 \cdot 7,9 \cdot 7 \\
(13-62)\end{array}$ & $\begin{array}{c}6 \cdot 3,4 \cdot 8 \\
(1 \cdot 0-13 \cdot 3)\end{array}$ \\
\hline Probable & 10 & $\begin{array}{l}33 \cdot 2,7 \cdot 8 \\
(19-46)\end{array}$ & $\begin{array}{l}1 \cdot 4,2 \cdot 1 \\
(0.6-3 \cdot 1)\end{array}$ \\
\hline Possible & 15 & $\begin{array}{l}25 \cdot 0,7 \cdot 0 \\
(18-32)\end{array}$ & $\begin{array}{c}1.4,0.9 \\
(0.4-2.3)\end{array}$ \\
\hline
\end{tabular}

minutes and consisted of 45 saccades divided into three 15 saccades periods. Target displacements had random amplitude $\left(20^{\circ}-40^{\circ}\right)$ and were spaced at random intervals (13 seconds). SEM parameters (PSV, SA, SL) were calculated by interpolation at $35^{\circ}$ of raw data. SEM normative data were obtained from a group of 160 drug free healthy volunteers recorded in our laboratory and ranging from 15 to 75 years of age. SEM were considered to be abnormal when differing from age-matched normative values by 2 SD.

The MRI examinations were obtained with a 0.5 tesla superconducting magnetic resonance imager (CGR). Slices were $1 \mathrm{~cm}$ thick. Multislice spin-echo studies were performed with echo time of $50 \mathrm{~ms}$ and a repeat time of $1,200 \mathrm{~ms}$, producing a relatively T2-weighted scan. All patients were imaged in the transverse plane and several in the coronal plane. All scans were evaluated for the number of lesions and confluence of lesions (defined as increased T2 signal in periventricular white matter of at least $2 \mathrm{~cm}$ in the greatest diameter). Size and distribution of lesions were also noted. Lesions were considered typical of multiple sclerosis if they were of high intensity on spin-echo, measured greater than 3 $\mathrm{mm}$ diameter, and were located predominantly in the white matter.

Statistical associations between results of a given test and clinical data were examined with the aid of contingency tables. Patients were finally reclassified according to Poser $e t$ al criteria, ${ }^{2}$ by using MRI and SEM analysis as paraclinical tests.

\section{Results}

The incidence of laboratory abnormalities in the three clinical categories of multiple sclerosis patients, classified according to McAlpine criteria, ' is reported in table 2. MRI proved to be more sensitive in the

Table 2 Incidence (\%) of abnormalities

\begin{tabular}{|c|c|c|c|c|c|c|}
\hline $\begin{array}{l}\text { Clinical } \\
\text { category of } \\
\text { multiple sclerosis }\end{array}$ & $M R I$ & $S E M$ & $P S V$ & $S A$ & $S L$ & SINO \\
\hline $\begin{array}{l}\text { Definite } \\
\text { Probable } \\
\text { Possible } \\
\text { Total }\end{array}$ & $\begin{array}{l}87 \cdot 5 \\
50 \cdot 0 \\
60 \cdot 0 \\
78 \cdot 2\end{array}$ & $\begin{array}{l}78 \cdot 1 \\
60 \cdot 0 \\
73 \cdot 3 \\
76 \cdot 3\end{array}$ & $\begin{array}{l}56 \cdot 0 \\
33 \cdot 3 \\
63 \cdot 6 \\
54 \cdot 7\end{array}$ & $\begin{array}{l}76 \cdot 0 \\
83 \cdot 3 \\
54 \cdot 5 \\
71 \cdot 4\end{array}$ & $\begin{array}{l}76 \cdot 0 \\
66 \cdot 6 \\
63 \cdot 6 \\
71 \cdot 4\end{array}$ & $\begin{array}{l}36 \cdot 0 \\
33 \cdot 3 \\
36 \cdot 3 \\
35 \cdot 7\end{array}$ \\
\hline
\end{tabular}

Table 3 Associations between laboratory findings and clinical data

\begin{tabular}{|c|c|c|c|c|c|c|}
\hline & $M R I$ & $S E M$ & $P S V$ & $S A$ & $S L$ & $S I N$ \\
\hline BS & - & $p<0.05$ & $p<0.05$ & - & - & - \\
\hline CBL & - & - & - & - & - & - \\
\hline $\begin{array}{l}\mathbf{P} \\
\mathbf{S}\end{array}$ & - & - & - . . & $\cdots$ & $-\cdots$ & $\div$ \\
\hline V & - & - & -- & - & $\mathrm{p}<0.05$ & - \\
\hline
\end{tabular}

MRI, SEM, PSV, SA, SL, SINO: see table 2. BS = brain stem signs; $\mathrm{CBL}=$ cerebellar signs; $\mathrm{P}=$ pyramidal signs; $\mathrm{S}=$ sensory signs; $\mathbf{V}=$ visual signs.

definite $(87.5 \%)$ group. SEM findings, that were considered abnormal when at least one of the three parameters (PSV, SA, SL) was abnormal, were found to be more sensitive in the probable $(60 \%)$ and possible (73.3\%) groups. Considering all the patients together the sensitivity of MRI $(78 \cdot 2 \%)$ was not very different from that of SEM $(76 \cdot 3 \%)$. If we look at SEM parameters individually, it can be noticed that SA and SL were equally sensitive $(71.4 \%)$, while PSV showed a lower sensitivity $(54.7 \%)$. The incidence of SINO was obtained considering both monolateral and bilateral SINO and it was almost the same in all clinical categories with an overall incidence of $35.7 \%$.

On MRI, all patients showed more than one plaque. The MRI abnormalities were mainly supratentoria periventricular $76.9 \%$, hemispheric $35.8 \%$, situated ig the centrum semiovale $10 \cdot 2 \%$. Very few subtentoria plaques were observed: in the brain stem $(10 \cdot 2 \%)$ and cerebellum $(25 \cdot 6 \%)$. Isolated subtentorial plaques were never found.

Associations between abnormal laboratory findings and clinical data are reported in table 3. Significant $(p<0.05)$ associations were found between BS signs and SEM abnormalities (at least one parameter impaired); between BS signs and PSV; and between V signs and SL.

No significant correlations were found when comparing supratentorial MRI localisations with PSV, SA and SL. Considering MRI findings all together, a

Table 4 Patients reclassified as multiple sclerosis laboratory supported definite when including MRI and SEM findings among Poser et al criteria

\begin{tabular}{lll}
\hline Patients & McAlpine category & Abnormal paraclinical evidences \\
\hline SR & Probable & CSF, MRI, SEM \\
SS & Probable & CSF, MRI, SEM \\
CL & Probable & CSF, MRI, SEM \\
OA & Probable & CSF, MRI, SEM \\
RA & Probable & CSF, MRI \\
AR & Probable & CSF, MRI, SEM \\
CM & Possible & CSF, MRI, SEM \\
LA & Possible & CSF, MRI, SEM \\
AC & Possible & CSF, SEM \\
BA & Possible & CSF, MRI, SEM \\
\hline
\end{tabular}

MRI, SEM: see table 2. CSF = cerebro spinal fluid. 
significant $(p<0.05)$ correlation with SEM and SA was found. The correlation between subtentorial MRI plaques and SEM findings was not assessed because of the very limited number of subtentorial MRI lesions. Twenty one of the 25 non definite patients were reclassified according to Poser et al $^{2}$ criteria, including MRI and SEM analysis among the paraclinical evidences of CNS lesions. Four patients could not be classified because their cerebrospinal fluid was normal. Ten $(47.6 \%)$ patients were reclassified as laboratory supported on the basis of MRI and SEM findings. Eight patients had both MRI and SEM positive; in two cases only one test was positive, either MRI or SEM (table 4).

Three patients had abnormal SEM analysis and normal MRI.

\section{Discussion}

Our findings on the incidence of MRI and SEM abnormalities in 57 patients (table 2) classified as having definite, probable and possible multiple sclerosis' suggest that both methods share the same sensitivity. Furthermore, if one considers only the non definite multiple sclerosis patients, SEM analysis showed a slightly better sensitivity. These findings must be regarded with caution owing to the limited number of non definite multiple sclerosis patients studied. It can be argued that SEM were considered pathological when only one of the three parameters (PSV, SA, SL) was impaired. The logic of such a decision, derived from the fact that the impairment of each SEM parameter could be regarded as the result of a single CNS lesion.

The fact that SL and SA proved to be more sensitive than PSV (table 2) could be explained on the basis of the different neurophysiological systems effecting the different SEM parameters. The wider the pathways explored the higher the expected sensitivity.

SINO findings were particularly interesting because they reflect the involvement of a very specific CNS structure, the medial longitudinal fasciculus. ${ }^{9}$ Also of interest is the significant ( $p<0.05$ ) correlation (table 3) between BS signs and PSV, and between V signs and SL. The former association confirms experimental and clinical data ${ }^{8}$ that attribute the control of PSV to the function of a structure located within the brain stem, the paramedian pontine reticular formation. The latter underlines the obvious importance of the visual system in the control of SL.

In conclusion, our data confirm the well documented $^{10-14}$ capability of MRI to detect CNS lesions, particularly in the periventricular ones which are important because they can be clinically silent and yet represent the majority of MRI lesions $(82.15 \%$ in our series). On the other hand, SEM analysis appeared to be very important for the study of the function of CNS structures such as brain stem and medial longitudinal fasciculus, that are not very well visualized by MRI.

Although our SEM findings need to be confirmed with more extensive data, it appears that SEM analysis may play an important role in the diagnosis of multiple sclerosis even in the era of MRI, and it may be included in the paraclinical tests of Poser et $a l^{2}$ to identify clinically silent CNS lesions in multiple sclerosis patients.

\section{References}

1 McAlpine D, Lumsden CE, Achensom ED. Multiple Sclerosis: A Reappraisal. Edinburgh: Churchill Livingstone, 1972.

2 Poser CM, Paty DW, Scheinberg L, et al. New criteria for multiple sclerosis: guidelines for research protocols. Ann Neurol 1983;13:227-31.

3 Mastaglia FL, Black JL, Collins DWK. Quantitative studies of saccadic eye movements in multiple sclerosis. Brain 1979;102:817-34.

4 Meienberg O, Muri R, Rabinau PA. Clinical and oculographic examinations of saccadic eye movements in the diagnosis of multiple sclerosis. Arch Neurol 1986;3:438-43.

5 Reulen JPH, Sanders EACM, Hogenhuis IAH. Eye movements disorders in multiple sclerosis and optic neuritis. Brain 1983;106:121-40.

6 Solingen DL, Baloh RW, Myers L, et al. Subclinical eye movements disorder in patients with multiple sclerosis. Neurology 1977;27:614-9.

7 Tackmann W, Strenge H, Barth R, et al. Evaluation of various brain structures in multiple sclerosis with multimodality evoked potentials, blink reflex and nistagmography. J Neurol 1980;224:33-46.

8 Leigh RJ, Zee DE. The saccadic system. In: Leigh RJ, Zee DE, eds. The Neurology of Eye Movements. Philadelphia: Davis Co, 1983:39-68.

9 Baloh RW, Yee RD, Honrubia V. Internuclear ophthalmoplegia. Arch Neurol 1978;35:484-89.

10 Farlow MR, Markand ON, Edwards MK, et al. Multiple sclerosis: Magnetic resonance imaging, evoked responses, and spinal fluid electrophoresis. Neurology 1986;36:828-31.

11 Jacobs L, Kinkel WR, Polachini I, et al. Correlations of nuclear magnetic resonance imaging, computerized tomography, and clinical profiles in multiple sclerosis. Neurology 1986;36:27-34.

12 Kirshener HS, Tsai SI, Runge VM, et al. Magnetic resonance imaging and other techniques in the diagnosis of multiple sclerosis. Arch Neurol 1985;42: 859-63.

13 Rumbach L, Warter JM, Marescaux C, et al. Multiple sclerosis diagnosis: magnetic resonance imaging compared with other paraclinical examinations. Eur Neurol 1987;27:92-6.

14 Uhlenbrock D, Seidel D, Gehlen W, et al. MR imaging in multiple sclerosis: comparison with clinical, CSF, and visual evoked potential findings. AJNR 1988;9:59-67.

15 Griffiths AN, Marshall RW, Richens A. Saccadic eye movements analysis as a measure of drug effects on human psychomotor performance. $\mathrm{Br} J$ Clin Pharmacol 1984;18:73S-82S. 